\title{
T1 Stage Finding
}

National Cancer Institute

\section{Source}

National Cancer Institute. T1 Stage Finding. NCI Thesaurus. Code C48720.

A clinical and/or pathologic primary tumor TNM finding indicating that the cancer is limited to the site of growth. 